\title{
Learning style from face-to-face to online learning in pandemic COVID-19 (the case study at East Java)
}

\author{
Desy Santi Rozakiyah*, Indah Yasminum Suhanti \& Seli Septiana Pratiwi \\ Universitas Negeri Malang, Malang City, Indonesia
}

\begin{abstract}
Distance education has been an alternative education during COVID-19 pandemic. This education is undertaken by children from different economic conditions. During the pandemic, there is no difference between children from high and low-income economies. This study was designed to determine how the education during the pandemic in Indonesia differentiates from one region to another. The study employed qualitative research with a case study approach. The results showed that students received a different education apart from distance education during the pandemic. In the odd-even semester, face-to-face learning was carried out at the junior and senior high school levels. In the elementary school setting, learning activities were done in the form of small study groups with face-to-face learning activities. In the university context, learning was carried out online or referred to as asynchronous and was done using media spaces such as Zoom, Google Meet and Google Classroom as a means of delivering material.
\end{abstract}

Keywords: distance learning, learning media in pandemic

\section{INTRODUCTION}

The impact of SAR-CoV-2 disease pandemic known as the Coronavirus (COVID-19) has become a factor for debate in carrying out education (Pozo-Rico et al. 2020). Emile Durkheim explained that in the sociological study of education, the existence of a process in education can develop children through socialization and interaction between friends (Pavlyshyn et al. 2019). The impact of learning changes during the pandemic base on psychology experiences students were stress and difficult (Wood et al. 2012). Therefore, during the pandemic, learning requires a new habit that all people never carried out in online learning (Panigrahi et al. 2018). Changing the paradigm of thinking in this pandemic period requires hard work and learning changes from face-to-face to online learning (Neuhauser 2002). The main characteristic of online learning is using technology to participate in learning and meeting in virtual situations (Paechter \& Maier 2010). Changing the paradigm of community thought or the thoughts of parents of students is very difficult because this pandemic has changed traditional learning to online learning, and this is needed as habituation in learning online, and student change their learning style from face to face to online learning. The concept of home learning has never been a discourse in national education. However, an epidemic like this forces the community to change the learning pattern to digital learning as a form of the popular education revolution in 2020 where children carry out school at home, which is a very difficult challenge for students' parents (Howland et al. 2006). The application of online learning has so far been limited to the use of internet networks, unlike in other countries, but the existence of a physical distancing policy to cut the spread of the epidemic forcing changes in formal education in school to being forced to learn from home with a national-scale online system. It means forcing parents and students to use online learning (Shalev-Shwartz 2011). For Indonesian people, using

*Corresponding author: desy.rozakiyah.fis@um.ac.id 
online learning is indeed very difficult and requires readiness. The most important thing is parents in accompany child in learning activity although they are not ready with the digital technology in education process.the problem of internet network access is that it is not available or reliable in all areas.

\section{REVIEW OF RELATED LITERATURE}

Implementing an online education system is not easy. In addition to personal discipline for independent learning, some facilities and resources must be provided. Since implementing education in this pandemic era, the most important thing has become safety to reduce the risk of children and teachers being affected by the COVID-19 disease pandemic (Alauddin et al. 2020). According to (Maslow 1987) related to needs of human needs depend on basic fulfilment, how the human get information in around as to prevent direct physical contact with other people this is a from of preventing the transmission of COVID-19. (Berry et al. 2020). Little consideration is needed to predict the impact of face-to-face learning activities during a pandemic (Monto et al. 1985). Closing schools aims to reduce the transmission of the COVID-19 pandemic (Chao et al. 2010). Learning online or distance learning is indeed very difficult for the community because there are various characteristics of the environment that must be considered, especially the availability of facilities at home for learning online (Moore et al. 2011). It takes patterns and habits for students and parents to accompany online learning. In addition, the ministry of education also issued policies related to the implementation of the curriculum in educational units in special conditions since the school system during the pandemic was not operating as usual. However, with a disease pandemic like this, a change in the learning paradigm must be carried out according to environmental conditions or school climate. This learning pattern can be seen in the learning theory known as behaviorism which shifted to constructivism, meaning that students construct knowledge through learning processes not transferred from teacher to student (Deschesnes et al. 2003). The importance of learning media used by schools can also assist students in participating in learning activities. The teacher's role in providing motivation to students is due to online learning, which results in students feeling bored in learning. Thus, the importance of the role as a teacher in motivating children is so that students can follow learning as well (Rurik et al. 2011). The role of accompanying teachers and parents during the pandemic is felt by all parents of students in accompanying and carrying out education at home (Subramani \& Venkatachalam 2019). From the results of research conducted by Hadi et al (Pajarianto 2020), the characteristics of learning carried out by children can cause differences in participating in learning activities. In short, it is caused by the facilities in home learning which depends on the awareness of the parents in assisting learning and the willingness to provide facilities for their children.

The prominent role of teachers and parents during the COVID-19 pandemic is to work together to succeed in distance learning. Therefore, cooperation is needed in providing motivation and learning support to children (Daniel 2011). As a form of implementing learning during a pandemic like this, teachers usually do it by applying a lot of learning models and methods, only applying student-centered learning and student creativity. These learning patterns are needed, which are called strategies in developing learning components with the aim of achieving learning. Parents' roles in schools contains humanistic behavior because they must pay attention to their students as holistic learners. Holistic learners have cognitive and affective needs, and the role of parents is to understand their children deeply, especially concerning psychological conditions (Suryani 2013).

\section{METHOD}

A field study is aimed to gather information from teachers, parents, and students. Thus, identifying patterns and behavior of teachers, parents and students in implementing this home learning. Thus, the results of this study examine face-to-face learning changes into online schools known as distance 
learning. Teachers, parents, and students were selected through sampling in the form of snowball sampling and then asked to be interviewed for 1 hour. Semi-structured interviews were conducted. Respondents were asked to explain how learning has transitioned from face-to-face to online. Interviews in the analysis used the basic theory as described by Creswell (Creswell 2009). The data collected was examined through a cooperative approach to classify the similarities and differences in the participants' perspectives involved in online learning activities. The coding process was undertaken to develop categories and themes which were carefully linked to the existing literature. In the end there will be research findings. The research credibility was obtained by prolonged involvement and intensive discussions with respondents.

\section{RESULT AND DISCUSSION}

Based on the findings, parents, teachers and students have difficulty following online learning and the workload of parents has also increased. Characteristics of online learning experience by students ranging from elementary school education to university levels is different because of elementary implementation learning like grouping student, while secondary school, senior high school and university get used to use online learning. The findings during the study showed the level of use of instructional media spaces used by students from elementary school to the university level, online learning media such as WhatsApp, Zoom, Google Meet, and Google Classroom were identified. For elementary education, the learning media room used was the WhatsApp learning media because parents find it easier to use and assist their children's learning activities. In addition, for schools that are in the red zone, students will be greeted by their teachers through Zoom and Google Meet. Junior high school, senior high school, and university students use WhatsApp, Zoom, Google Meet and Google Classroom. But something is interesting in high school education, which is that they carry out learning by applying odd and even student absences to take turns doing face-to-face learning at school. As for the university level, apart from the learning media space used, lecturers deliver material through videos uploaded to YouTube and podcasts as a medium for delivering material to students.

Many parents complain and cannot follow and overcome the problems experienced by their children. But it is different for the parents of students who have a higher educational background and who are younger to monitor and guide their children in carrying out learning activities. In addition, the psychology of students in carrying out online education starts from elementary school and impacts up to university levels. Students tend to be bored and lazy in following the learning that takes place. This is motivated by the teacher's many tasks in almost every subject and the fact that they have to complete the assignment given by the teacher.

Carrying out education during a pandemic is very difficult since it needs cooperation between teachers and schools and readiness in carrying out school at home (Daniel 2020). Parental support is very important for children to support learning activities during a pandemic like this. The goal is to maintain psychological and physical health. In carrying out learning activities in children (Alivernini \& Lucidi 2011), psychological service readiness is also prepared to maintain the health of children and adults during a pandemic, as well as a form of concern and handling during a pandemic (Bell et al. 2020). As parents, providing support in carrying out education is not as usual because skills in assisting children in carrying out learning tasks while at home are very difficult things and need many aspects that need attention (Uchino 2009). In addition to perceived social support for predicting student perceptions, control and identification with schools to foster children's academic achievement, thereby reducing the likelihood of children dropping out of school (Fall \& Roberts 2012). The existence of a platform in learning activities carried out by teachers and students in carrying out learning activities such as learning through Zoom, WhatsApp and Google Classroom as a form of teacher policy in conveying learning occurs (Thalheim et al. 2003). This is because a lockdown that affects the learning system and patterns is not implemented as school would normally be. This media is used starting from elementary school to tertiary education instead of learning the E-learning system (Lee 2006). In addition, learning during a pandemic like this is 
more focused on learning (student centered) and a constructivist approach. In addition, the role of the teacher uses the context of learning methods where students are required to learn independently. During a pandemic like this, the use of textbooks that teachers usually given to students are now turning to digital books as a means of development and learning (Maki et al. 2000).

\section{CONCLUSION}

Changes in student learning styles caused by the COVID-19 disease start from how to change the paradigm and behavior patterns of students and parents in accompanying them while home learning is in progress. It can be proven how parents and teachers need habituation and readiness to assist children in carrying out school at home. Online learning application took many risks experienced by students, starting from parents who cannot use technology, lack of internet networks and the barrier of children carrying out online learning feeling bored due to the teacher's large number of tasks to students.

\section{REFERENCES}

Alauddin, M. et al. (2020) 'How can process safety and a risk management approach guide pandemic risk management?', Journal of Loss Prevention in the Process Industries. doi: 10.1016/j.jlp.2020.104310.

Alivernini, F. and Lucidi, F. (2011) 'Relationship between social context, self-efficacy, motivation, academic achievement, and intention to drop out of high school: A longitudinal study', Journal of Educational Research. doi: 10.1080/00220671003728062.

Bell, D. J. et al. (2020) 'Health service psychology education and training in the time of COVID-19: Challenges and opportunities', American Psychologist. doi: 10.1037/amp0000673.

Berry, L. L. et al. (2020) 'Service Safety in the Pandemic Age', Journal of Service Research. doi: $10.1177 / 1094670520944608$.

Chao, D. L., Elizabeth Halloran, M. and Longini, I. M. (2010) 'School opening dates predict pandemic influenza A(H1N1) outbreaks in the United States', Journal of Infectious Diseases. doi: 10.1086/655810.

Creswell, J. W. (2009) RESEARCH DESIGN Qualitative, Quantitative, and Mixed Methods Approaches, SAGE Publications. doi: 10.2307/1523157.

Daniel, G. (2011) 'Family-school partnerships: Towards sustainable pedagogical practice’, Asia-Pacific Journal of Teacher Education. doi: 10.1080/1359866X.2011.560651.

Daniel, S. J. (2020) 'Education and the COVID-19 pandemic', Prospects. doi: 10.1007/s11125-020-09464-3.

Deschesnes, M., Martin, C. and Hill, A. J. (2003) 'Comprehensive approaches to school health promotion: How to achieve broader implementation?', Health Promotion International. doi: 10.1093/heapro/dag410.

Fall, A. M. and Roberts, G. (2012) 'High school dropouts: Interactions between social context, self-perceptions, school engagement, and student dropout', Journal of Adolescence. doi: 10.1016/j.adolescence.2011.11.004.

Howland, A. et al. (2006) 'School Liaisons: Bridging the Gap between Home and School', School Community Journal.

Lee, Y. C. (2006) 'An empirical investigation into factors influencing the adoption of an e-learning system', Online Information Review. doi: 10.1108/14684520610706406.

Maki, R. H. et al. (2000) 'Evaluation of a Web-based introductory psychology course: I. Learning and satisfaction in on-line versus lecture courses', Behavior Research Methods, Instruments, and Computers. doi: 10.3758/BF03207788.

Maslow, A. H. (1987) Motivation and personality, 3rd ed., Motivation and personality, $3 \mathrm{rd}$ ed.

Monto, A. S., Koopman, J. S. and Longini, I. M. (1985) 'Tecumseh study of illness. XIII. Influenza infection and disease, 1976-1981', American Journal of Epidemiology. doi: 10.1093/oxfordjournals.aje.a114052.

Moore, J. L., Dickson-Deane, C. and Galyen, K. (2011) 'E-Learning, online learning, and distance learning environments: Are they the same?', Internet and Higher Education. doi: 10.1016/j.iheduc.2010.10.001.

Neuhauser, C. (2002) 'Learning Style and Effectiveness of Online and Face-to-Face Instruction', International Journal of Phytoremediation. doi: 10.1207/S15389286AJDE1602_4.

Paechter, M. and Maier, B. (2010) 'Online or face-to-face? Students' experiences and preferences in e-learning', Internet and Higher Education. doi: 10.1016/j.iheduc.2010.09.004.

Pajarianto, D. (2020) 'Study from Home in the Middle of the COVID-19 Pandemic: Analysis of Religiosity, Teacher, and Parents Support Against Academic Stress'. 
Panigrahi, R., Srivastava, P. R. and Sharma, D. (2018) 'Online learning: Adoption, continuance, and learning outcome-A review of literature', International Journal of Information Management. doi: 10.1016/j.ijinfomgt.2018.05.005.

Pavlyshyn, L. et al. (2019) 'Ethical problems concerning dialectic interaction of culture and civilization', Journal of Social Studies Education Research.

Pozo-Rico, T. et al. (2020) 'Teacher training can make a difference: tools to overcome the impact of COVID-19 on primary schools. An experimental study', International Journal of Environmental Research and Public Health. doi: 10.3390/ijerph17228633.

Rurik, I. et al. (2011) 'Knowledge, motivation, and attitudes of Hungarian family physicians toward pandemic influenza vaccination in the 2009/10 influenza season: Questionnaire study', Croatian Medical Journal. doi: $10.3325 / \mathrm{cmj} .2011 .52 .134$.

Shalev-Shwartz, S. (2011) 'Online learning and online convex optimization', Foundations and Trends in Machine Learning. doi: 10.1561/2200000018.

Subramani, C. and Venkatachalam, J. (2019) 'Parental Expectations and Its Relation to Academic Stress among School Students'.

Suryani, A. (2013) 'Home-School Interaction: Remodelling A Framework Of Parents-Teachers Relationship For Supporting Students'learning', JURNAL SOSIAL HUMANIORA (JSH), 6(1), pp. 1-19.

Thalheim, B., Binemann-Zdanowicz, A. and Tschiedel, B. (2003) 'Content modeling for e-learning services', in Proceedings of the 7th World Multi-Conference on Systemics, Cybernetics and Informatics (SCI 2003).

Uchino, B. N. (2009) 'Understanding the Links Between Social Support and Physical Health: A Life-Span Perspective With Emphasis on the Separability of Perceived and Received Support', Perspectives on Psychological Science. doi: 10.1111/j.1745-6924.2009.01122.x.

Wood, L., Ntaote, G. M. and Theron, L. (2012) 'Supporting Lesotho teachers to develop resilience in the face of the HIV and AIDS pandemic', Teaching and Teacher Education. doi: 10.1016/j.tate.2011.11.009. 